\title{
Prevalence of Streptococcus Pneumoniae and Mycobacterium Tuberculosis Co-Infection among HIV Infected Adult Patients on HAART in Ogun State, Nigeria
}

\author{
Enitan Seyi Samson ${ }^{1 *}$, Adekunbi Oluyemisi Ajike ${ }^{1}$, Ihonge John Cletus ${ }^{1}$, and Olumide Abiodun ${ }^{2}$ \\ ${ }^{1}$ Department of Medical Laboratory Science, Babcock University, Nigeria \\ ${ }^{2}$ Department of Community Medicine, Babcock University Teaching Hospital, Nigeria \\ *Corresponding author: Enitan Seyi Samson, Department of Medical Laboratory Science, Babcock \\ University, Ilishan-Remo, Ogun State, Nigeria, Tel: +2348065483761
}

\begin{abstract}
Background: Respiratory tract infections with more than one organisms are common in immunosuppressed patients, especially those who are Human immunodeficiency virus (HIV) positive. Mycobacterium tuberculosis and Streptococcus pneumoniae are the most important and dangerous pulmonary bacterial pathogens with global impact. This present study assessed the prevalence of Streptococcus pneumoniae and Mycobacterium tuberculosis co-infection and associated risk factors among HIV infected Adult Patients on Highly Active Antiretroviral Therapy (HAART) attending the HIV Clinic, Babcock University Teaching Hospital (BUTH), Ilishan-Remo, Ogun State, Nigeria.
\end{abstract}

Methods: Consenting 260 Participants (88 males and 172 females) with HIV positive status confirmed using, Determine HIV-1/2, Statpak HIV-1/2, and UniGold HIV-1/2 kits were randomly recruited for the study. Three consecutive early morning sputum specimens were requested from each participant in a disposable wide-mouthed, screw-cap, leakproof sputum container examined both macroscopically and microscopically without delay using standard microbiological methods. Streptococcus pneumoniae was detected using Culture, Gram staining technique, bile solubility test and Optochin sensitivity test, while Mycobacterium tuberculosis was detected using the Ziehl-Neelsen staining technique. Prior to the specimen collection, demographic and clinical information of the subjects were obtained using prepared questionnaires which were administered to the participants and handled with utmost confidentiality.

Results: Out of 260 participants examined, 23 (8.8\%) were positive for Streptococcus pneumonia infection. The recovered S. pneumoniae isolates were sensitive to Septrin $(78.3 \%)$, Gentamycin (73.9\%), Ciprofloxacin (69.5\%), Erythromycin (69.5\%), Ampiclox (65.2\%) and Amoxycillin (56.5\%). Also, 56
$(21.5 \%)$ of the 260 participants were positive for Mycobacterium tuberculosis infection; while 7 (2.7\%) were positive for Streptococcus pneumoniae and Mycobacterium tuberculosis co-infection. Gender, marital status, religion, educational level and occupation were significantly $(P<$ 0.05 ) associated with the prevalence of Streptococcus pneumoniae and Mycobacterium tuberculosis co-infection among the study participants. Identified risk factors include poor knowledge/awareness, history of pneumonia and tuberculosis, history of respiratory pathology and thoracic surgery, lack of vaccination with BCG and pneumococcal vaccine and less medical check-up.

Conclusion: This study confirms that co-pulmonary infection caused by $S$. pneumoniae and $M$. tuberculosis exist among HIV Patients on HAART in Ogun State, hence the need for greater public awareness, avoidance of implicated risk factors, regular medical check-up and immediate medical attention as the case may be, to avoid potential future complications associated with Streptococcus pneumoniae and Mycobacterium tuberculosis co-infectivity among HIV positive populace.

\section{Keywords}

HIV, HAART, Respiratory tract infection, Streptococcus pneumoniae, Mycobacterium tuberculosis
Abbreviations
RTI: Respiratory Tract Infection; HIV: Human Immunodefi- ciency Virus; AIDS: Acquired Immunodeficiency Syndrome; HAART: Highly Active Anti-Retroviral Therapy; TB: Tuber- culosis; SSA: Sub-Saharan Africa; CD4: Cluster of Differ- entiation 4

Citation: Samson ES, Ajike AO, Cletus IJ, Abiodun O (2019) Prevalence of Streptococcus Pneumoniae and Mycobacterium Tuberculosis Co-Infection among HIV Infected Adult Patients on HAART in Ogun State, Nigeria. Int J Virol AIDS 6:048. doi.org/10.23937/2469-567X/1510048

Accepted: March 11, 2019: Published: March 13, 2019

Copyright: (C) 2019 Samson ES, et al. This is an open-access article distributed under the terms of the Creative Commons Attribution License, which permits unrestricted use, distribution, and reproduction in any medium, provided the original author and source are credited. 


\section{Introduction}

Human immunodeficiency virus (HIV) infection is a serious threat and a major public health problem in tropical countries like Nigeria [1,2]. Among other concerns, HIV infection causes alteration in several lines of host defenses in the respiratory tract that contribute to an increased risk for pulmonary infection and its attending complications [3]. These alterations include abnormalities in mucociliary function and soluble defense molecules, such as defensins within respiratory secretions. Within the lung parenchyma, innate and adaptive immune responses to pathogens may be impaired. For example, alveolar macrophages from HIVinfected individuals have been shown to be deficient in pathogen recognition. Besides, HIV also results in chronic stimulation and activation of inflammatory cells within the alveolar space [4]. Progressive attack and elimination of the alveolar macrophages and CD4 cells in particular, by the virus makes respiratory tract infection common among HIV positive patients $[3,5]$ and a wide array of opportunistic pathogens (bacteria, fungi, parasites and other viruses inclusive), armed with different virulent factors have been found to co-exist $[4,6,7]$.

Streptococcus pneumoniae and Mycobacterium tuberculosis in particular, are the most important and dangerous bacterial pathogens of respiratory tract infection and their co-existence in immunosuppressed patients, especially those who are HIV positive have been documented [5,8-10]. Their prevalence depends on geographical region and the CD4 cell count in the patients infected with HIV. While pneumonia was the most important and common reason of mortality in patients with HIV in the USA and European countries, before the advent of Highly Active Anti-Retroviral Therapy (HAART) and Co-trimoxazole as prophylaxis, tuberculosis was the most prevalent infectious disease in the African regions [11]. Together, pneumonia and tuberculosis has been a major co-morbidity in HIV infected individuals since the begin of the HIV epidemic [3].

Streptococcus pneumoniae accounts for over $60 \%$ of bacterial pneumonia of adults who require hospitalization [12]. It is a gram-positive diplococcus with thick capsule, which is responsible for the organism's virulence. Incubation period is about 1-3 days. The typical symptoms include cough, fever, chest pain and sputum production. Predisposing factors include: immunosuppression, alcoholism, smoking, influenza, chronic disease of the lung or heart etc. This condition develops when the organism is inhaled into the alveoli of a susceptible host, multiply rapidly, and cause an inflammatory response. Fibrinous edema fluid and phagocytic cells pour into the air sacs of the lung, causing difficulty in breathing and sputum production. This increase in fluid produces abnormal shadows on $X$-ray films of the chest in patients $[13,14]$.
Furthermore, Streptococcal pneumoniae infections have emerged as an important cause of morbidity and mortality in individuals infected with the human immunodeficiency virus. HIV-1 seropositive individuals are particularly susceptible to infections with encapsulated bacteria, such as Streptococcus pneumoniae because of defects in both cell-mediated and humoral immunity [15-17].

Pneumococcal disease can occur at any time during the course of HIV-1 infection [18]. Although pneumococcal disease can be an early manifestation of HIV-1 infection, its incidence increases as HIV-1 disease progresses [19-21]. Wallace and co-workers described the pulmonary diseases in HIV-1 infected individuals in a prospective multicentre study in which subjects were followed for 18 months [6]. Overall, bacterial pneumonia (4.9\%) was more common than Pneumocystis carinii pneumonia (3.9\%). In their studies, S. pneumoniae was the most common pathogen isolated: 13 of 30 cases in which a pathogen was isolated.

In another study, the risk factors for the development of bacterial pneumonia were evaluated in a multicentre observational study in which 1,130 patients with HIV-1 infection were monitored for nearly 5 years [19]. The rate of bacterial pneumonia among the HIV-1 seropositive subjects was 5.5 per 100 person/year compared with 0.9 per 100 person/year in the seronegative controls. The risk of pneumonia increased as the CD4 lymphocyte count declined and the rate was highest in those persons with CD4 counts less than 200 cells/ $\mathrm{mm}^{3}$. Still, in a nested case-control study, investigators at Johns Hopkins Medical Centre reported that HIV-1 infected patients with pneumococcal pneumonia were more likely than controls to be African-American, have $<200 \mathrm{CD} 4$ cells $/ \mathrm{mm}^{3}$, have a history of previous pneumonia, and have an albumin $<3.0 \mathrm{~g} / \mathrm{dL}$ [20]. The use of zidovudine and previous pneumococcal vaccination when the subject had $>200 \mathrm{CD} 4$ cells $/ \mathrm{mm}^{3}$ were less common in cases than in controls [22].

Mycobacterium tuberculosis on the other hand, causes a chronic infection of the lungs (and often other body organs) called tuberculosis (TB). The condition is characterized by slight fever, weight loss, sweating at night and chronic cough productive of blood-streaked sputum [23]. The organism is a slender, strongly acidfast, rod shaped bacterium that stains in an irregular fashion. It is a strict slow-growing aerobe and its virulence depends on its ability to survive within host macrophages. Incubation period is within 2-10 weeks. It infects a one third of the world's population with $95 \%$ of those infected living in developing countries. In 2010, WHO estimated that there were 8.8 million new cases of tuberculosis with 1.75 million deaths [24].

Mortality rates are highest among children and young adults. Factors contributing to the high prevalence of tuberculosis in developing countries and prob- 
lems in its control include co-infection with HIV (single most important factor), emergence of multi-drug resistant tuberculosis, inadequate treatment, continuing poverty, malnutrition, overcrowding, armed conflict and increasing numbers of displaced persons. Infection with HIV greatly increases the risk of developing tuberculosis and accelerates its progress. Progression to AIDS is also accelerated in those co-infected and HIV has a significant effect on the risk of relapse of tuberculosis [25]. According to Crook, et al. [26], HIV is the most important cause of the increasing incidence of tuberculosis in sub-Saharan Africa (SSA). Up to $70 \%$ of those with tuberculosis are also HIV positive.

The World Health Organization (WHO) estimates that tuberculosis causes up to $40 \%$ of AIDS deaths in sub-Saharan Africa and Southeast Asia [27]. The number of people who died from TB in 2010 were about 1.4 million, including 350,000 people with HIV, equal to 3,800 deaths a day [24]. The WHO Stop TB Partnership also estimates that TB causes possibly as many as $50 \%$ of these deaths. Globally, almost $10 \%$ of all new TB cases are HIV positive, but this number varies widely on a country basis and can be as high as $80 \%$. TB and HIV/AIDS co-infection form a lethal combination, each accelerating the other's progress. It is estimated that without preventive TB treatment as many as one in three people infected with HIV will develop TB. An HIV positive person infected with TB is up to 50 times more likely to become sick with TB than someone infected with TB who is HIV negative. In fact, TB is the most common opportunistic infection in people living with HIV/AIDS [28]. The lifetime risk of developing TB is $5 \%$ to $10 \%$ if HIV negative and $50 \%$ if HIV positive. HIV/AIDS is fuelling a continued increase in TB incidence, making it more and more difficult for health systems to keep up with increasing demands for health services for both diseases $[29,30]$.

Many people infected with HIV in developing countries develop TB as the first manifestation of AIDS. The two diseases represent a deadly combination because together they are more destructive than either disease alone. TB is harder to diagnose and progresses faster in HIV-infected people. Also, in HIVpositive people, is almost certain to be rapidly fatal if undiagnosed or left untreated. It can occur early in the course of HIV infection [28,30].

Furthermore, in HIV infected patients with severe immunosuppression, it is well recognized that more than one infection can co-exist. Concurrent pulmonary TB and Pneumococcal pneumonia has been well described in reports from African countries, but few studies have been performed in Europe or the US. Co-infection of $S$. pneumoniae and $M$. tuberculosis is considered defining disease of Acquired Immunodeficiency Syndrome [5]. Their establishment in any individual depends on if certain conditions are favourable such as smoking, crowded environment, use of drugs, malnutrition and use of steroids (Hence low $\mathrm{CD}^{+}$cell count in patients may be indicated by Streptococcus pneumoniae and Mycobacterium tuberculosis co-infection in HIV Patients). According to Ihongbe, et al. [5], this may help to identify a population of unknown AIDS patient.

When HIV infection is left untreated within the first ten years of infection, majority of the patients develop fatal opportunistic infections as a result of HIV induced deficiencies in the immune system. Coinfection of $S$. pneumoniae and $M$. tuberculosis among HIV infected persons has contributed significantly to the mortality and morbidity rates of HIV/AIDS globally. These opportunistic pathogens are common causes of lower respiratory tract infections in HIV infected patients, with similar clinical and radiological features. However, the prevalence rate of such co-infection and level of awareness among HIV positive populace is not well documented. Many reports are published on coinfection of more than one microorganism in most of the internal organs. However, there are few reports on the co-infection of an internal organ such as lung with two microorganisms [5,8-10,31].

Early detection of Streptococcus pneumoniae and Mycobacterium tuberculosis co-infection and prompt initiation of therapy will halt further depletion of CD4 cells and rapid progression to AIDS in HIV infected patients. However, to the best of our knowledge, the prevalence rate of Streptococcus pneumoniae and Mycobacterium tuberculosis co-infection among HIV infected adult patients on HAART in Ogun State is not known. Besides, the distribution of symptomatic and asymptomatic cases in Ogun state is not documented. There is also need to continue to monitor the sensitivity pattern of Streptococcus pneumoniae isolates to the available antibiotics so as to ensure that there are little or no cases of multiple drug resistance, as well as to guide the Clinicians in their drug prescription efforts, scarcity of information in this regard necessitates this study.

The aim of this study is therefore to determine the prevalence rate of Streptococcus pneumoniae and Mycobacterium tuberculosis co-infection and associated risk factors among HIV infected adult patients on HAART attending the HIV Clinic of Babcock University Teaching Hospital, Ilishan-Remo, Ogun State, Nigeria and also to determine the antibiotic sensitivity pattern of the Streptococcus pneumoniae isolates recovered from the HIV infected adult patients on HAART.

\section{Methods}

\section{Study area}

The study was carried out among HIV infected patients attending HIV Clinic, Babcock University Teaching Hospital (BUTH), Ilishan-Remo, Ogun State. BUTH is a 300-bed space capacity Private Hospital and 
the only Tertiary Medical Centre in the community. While Ilishan-Remo Community is one of the geo-political wards in Ikenne Local Government Area of Ogun State, situated in the tropical area of South-western part of Nigeria, coordinates: $7^{\circ} 29^{\prime} 00^{\prime \prime} \mathrm{N}, 2^{\circ} 53^{\prime} 00^{\prime \prime} \mathrm{E}$.

\section{Duration of study}

This study lasted for a period of three months (March-May 2018).

\section{Study design}

The study was a prospective research on the prevalence of Streptococcus pneumoniae and Mycobacterium tuberculosis co-infection among HIV infected patient on HAART.

\section{Sample size calculation}

The sample size (n) was estimated using the population proportion formula:

$\mathrm{N}=\mathrm{Z}^{2} \mathrm{PQ} / \mathrm{d}^{2}$

Where;

$\mathrm{N}=$ required sample size

$Z=$ Standard normal variant at $5 \%(p<0.05)$ error or 95\% confidence interval is 1.96

$\mathrm{P}=$ Proportion of HIV positive patients co-infected with Mycobacterium tuberculosis from previous study

$\mathrm{Q}=$ Proportion of HIV positive patients without Mycobacterium tuberculosis co-infection (1-P) and

$d=$ Absolute error margin is 0.05

For the calculation, a 95\% confidence interval, a P-value of 0.216 , i.e., a prevalence rate of $21.6 \%$ from previous study by Adejumo, et al. [32] and margin of error (d) set at 0.05 was used and a minimum sample size of 260 was obtained.

\section{Sample size}

A total of 260 HIV infected patients attending the HIV Clinic of Babcock University Teaching Hospital (BUTH), Ilishan-Remo, Ogun State, Nigeria were recruited for the study.

\section{Ethical consideration}

Ethical approval for the study was obtained from the Babcock University Health Research Ethics Committee (BUHREC), Babcock University, Ilishan-Remo, Ogun State, Nigeria, with the ethical approval registration number: BUHREC288/18. Also, administrative clearance for this study was obtained from the management of Babcock University Teaching Hospital (BUTH), IlishanRemo, Ogun State.

\section{Eligibility of Subjects}

\section{Inclusion criteria}

Consenting HIV infected patients on HAART, with
HIV status confirmed using, Determine HIV-1/2, Statpak HIV-1/2, and UniGold HIV-1/2 kits attending HIV Clinic, Babcock University Teaching Hospital, Ilishan-Remo, Ogun State, who were not on antibiotics in the preceding two weeks were randomly selected for the study.

\section{Exclusion criteria}

HIV positive patients on antibiotics in the preceding two weeks, HAART-naïve HIV positive patients, as well as HIV negative Patients were excluded from the study.

\section{Consent}

Informed consent was obtained from each participant before commencing the study. The purpose and nature of the study was properly explained to them and thereafter, the intended participants were requested to complete a consent form which they endorsed by a signature indicating their willingness to participate without any form of coercion.

\section{Data collection}

Prior to the specimen collection, demographic and clinical information of the subjects were obtained using prepared questionnaires which were administered to the participants. Each questionnaire had a unique participant identification number (PIDN). The pre-test questionnaires were administered to the participants directly. Those who were illiterate were assisted with translation before the questionnaires were completed. The first part of the questionnaires contained the bio-data of the participants such as age, marital status, occupation and level of education. The second part included clinical data relating to brief history suggestive of pulmonary infections. The study population was stratified by age, occupational, marital and educational status. All filled questionnaires were examined for completeness daily and stored securely in a locker. Data entries were done on the following day. For each participant, only the PIDN was recorded on the laboratory forms (no names) for the purpose of confidentiality. All the filled questionnaires were destroyed after data entry was completed.

\section{Specimen collection, transportation and storage}

Three consecutive early morning sputum specimens were requested from each participant in a disposable wide-mouthed, screw-cap, leak-proof sputum container. They were instructed to properly rinse their mouth before producing the sputum, inhale deeply 2-3 times, cough up deeply from the chest and spit in the sputum container by bringing it closer to the mouth. This was done in a well-ventilated environment, very close to the window for biosafety purpose. Adequate precaution was taken to avoid the spread of aerosols and contamination of the outside of the container with sputum. When spillage occurred, participants were instructed to properly clean up outside of the container with the tissue paper soaked in phenol containing disinfectant 
provided before submission of the specimen was made. Lastly, each specimen was labelled accordingly with the PIDN. Salivary samples were rejected as they are unsuitable for microbiological investigations. And due to the fragility of Streptococcus pneumoniae, purulent part of the sputum was transferred to a cotton wool swab and insert in a container of Amies transport medium, delivered promptly to the laboratory and cultured without any delay (No refrigeration of specimen in this case). The Amies transport medium helped Streptococcus pneumoniae (if present) to survive and avoid overgrowth of fast multiplying commensals.

\section{Laboratory Diagnosis}

\section{Sputum macroscopy}

The sputum specimens were examined and the physical appearances (whether purulent, mucopurulent, mucoid, mucosalivary or bloody) were noted.

\section{Sputum microscopy}

Gram and Ziehl-Neelson stained sputum smears were examined microscopically for the detection of $S$. pneumoniae and M. tuberculosis, respectively, as described by Cheesbrough [33]. The former if present appeared as Gram positive diplococci, while the latter appeared as red (Acid fast), slightly curved rods, occurring singly or in small groups.

\section{Sputum culture}

Using a sterile applicator stick, each sputum sample was inoculated on a Chocolate agar and MacConkey agar as described by Joon, et al. [34]. The culture plates were incubated at $37{ }^{\circ} \mathrm{C}$ for $18-24$ hours in a candle jar with a piece of wet, sterile cotton placed in it, to provide a $5-10 \% \mathrm{CO}_{2}$ atmosphere and humid environment. Also, an optochin disc $(5 \mu \mathrm{g})$ was placed on the inoculated Blood agar and incubated aerobically (not in $\mathrm{CO}_{2}$ ). This helped to provide a rapid presumptive identification of $S$. pneumoniae which is sensitive to optochin (ethylhydrocupreine hydrochloride). The zone of inhibition was at least $10 \mathrm{~mm}$. Suspected colonies with zone of inhibition less than $10 \mathrm{~mm}$ (i.e., $6 \mathrm{~mm}$ diameter) were later tested for bile solubility before been discarded.

\section{Characterization of Isolates}

The morphological appearances of the bacterial colonies were examined based on size, colour, opacity, surface, shape, consistency, haemolysis, edge, elevation, and pigmentation. Suspected isolates of $S$. pneumoniae were characterised using standard biochemical tests including: Catalase test, Bile solubility test and Optochin sensitivity test as described by Cheesbrough [35].

\section{Determination of the antibiotic sensitivity pattern of Streptococcus Pneumoniae isolates}

The antibiotic sensitivity pattern of the Streptococcus pneumoniae isolates was determined using the modified Kirby-Bauer disc diffusion technique as described by Bauer, et al. [36] and Cheesbrough [37]. With the aid of Standard Interpretative Chart, the zones sizes of each antibiotic was interpreted and the isolate reported as either 'Resistant' or 'Susceptible'.

\section{Data analysis}

Raw data was entered in Microsoft Excel. Statistical analysis was carried out using SPSS Statistics software package (version 18.0). One-way analysis of variance (ANOVA) and Turkey-Kramer Multiple Comparisons Test was used to compare the prevalence of Streptococcus pneumoniae and Mycobacterium tuberculosis co-infection among HIV infected patients on HAART attending Babcock University Teaching Hospital, Ilishan-Remo, Ogun State according to their socio-demographic characteristics. P-values $<0.05$ were considered significant.

\section{Results}

The present study investigated the prevalence of Streptococcus pneumoniae and Mycobacterium tuberculosis co-infection among HIV infected Adult Patients on Highly Active Antiretroviral Therapy (HAART) in Ogun State. Table 1 shows the sociodemographic characteristics of the participants. A total of 260 participants were examined. Based on their gender distribution, 172 (66.2\%) of them were females,

Table 1: Socio-demographic characteristics of the participants.

\begin{tabular}{|c|c|c|}
\hline Characteristics & Category & Number (\%) \\
\hline \multirow[t]{3}{*}{ Gender } & Male & $88(33.8)$ \\
\hline & Female & $172(66.2)$ \\
\hline & Total & $260(100.0)$ \\
\hline \multirow[t]{5}{*}{ Age range } & $18-37$ years & $104(40.0)$ \\
\hline & $38-57$ years & $94(36.2)$ \\
\hline & $58-77$ years & $36(13.8)$ \\
\hline & $78-97$ years & $26(10.0)$ \\
\hline & Total & $260(100.0)$ \\
\hline \multirow[t]{6}{*}{ Marital status } & Single & $139(53.5)$ \\
\hline & Married & $20(7.7)$ \\
\hline & Divorced & $40(15.4)$ \\
\hline & Separated & $57(21.9)$ \\
\hline & Widow & $4(1.5)$ \\
\hline & Total & $260(100.0)$ \\
\hline \multirow[t]{4}{*}{ Religion } & Christianity & 139 (53.5) \\
\hline & Islam & $105(40.4)$ \\
\hline & Traditional & $16(6.2)$ \\
\hline & Total & $260(100.0)$ \\
\hline \multirow[t]{5}{*}{ Tribe } & Yoruba & $154(59.2)$ \\
\hline & Igbo & $21(8.1)$ \\
\hline & Hausa & $33(12.7)$ \\
\hline & Others & $52(20.0)$ \\
\hline & Total & $260(100.0)$ \\
\hline
\end{tabular}




\begin{tabular}{|l|l|l|}
\hline Educational Levels & None & $121(46.5)$ \\
\hline & Primary & $26(10.0)$ \\
\hline & Secondary & $46(17.7)$ \\
\hline & Tertiary & $66(25.4)$ \\
\hline & Total & $260(100.0)$ \\
\hline Occupation & Self employed & $142(54.6)$ \\
\hline & Trader & $20(7.7)$ \\
\hline Student & $34(13.1)$ \\
\hline & Civil Servant & $59(22.7)$ \\
\hline & Unemployed & $5(1.9)$ \\
\hline & Total & $260(100.0)$ \\
\hline
\end{tabular}

while the remaining 88 (33.8\%) were males. 104 (40\%) of the participants were within the age range of 18-37 years, followed by $38-57$ years $(36.2 \%), 58-77$ years $(13.8 \%)$ and lastly $78-97$ years $(10.0 \%)$. The marital status of the participants was as follows: single (53.5\%), married $(7.7 \%)$, divorced $(15.4 \%)$, separated $(21.9 \%)$ and widowed (1.5\%). Based on their religion, 53.5\% were Christians, $40.4 \%$ were Muslims and $6.2 \%$ practice Traditional religion.

The frequency of Anti-retroviral therapy drug combinations among the participants is presented in Table 2. Drugs used include: Tenofovir, Atazanadir,

Table 2: Frequency of Anti-Retroviral Therapy drug combinations among the participants.

\begin{tabular}{|c|c|c|c|c|c|}
\hline Drugs & Response & Total N (\%) & $\begin{array}{l}\text { Double combination } \\
\mathrm{N}(\%)\end{array}$ & $\begin{array}{l}\text { Triple combination } \\
\text { N (\%) }\end{array}$ & $\begin{array}{l}\text { Quadruple combination } \\
\text { N (\%) }\end{array}$ \\
\hline \multirow[t]{3}{*}{ Tenofovir } & No & 93 (35.77) & $21(8.07)$ & 72 (27.69) & $0(0)$ \\
\hline & Yes & $167(64.23)$ & $0(0)$ & $120(46.15)$ & $47(18.08)$ \\
\hline & Total & $260(100)$ & $21(8.07)$ & $192(73.84)$ & 47 (18.08) \\
\hline \multirow[t]{3}{*}{ Atazanavir } & No & 160 (61.5) & $21(8.07)$ & $125(48.07)$ & $14(5.38)$ \\
\hline & Yes & $100(38.46)$ & $0(0)$ & 67 (25.77) & 33 (12.69) \\
\hline & Total & $260(100)$ & $21(8.07)$ & $192(73.84)$ & $47(18.08)$ \\
\hline \multirow[t]{3}{*}{ Lamivudine } & No & $0(0)$ & $0(0)$ & $0(0)$ & $0(0)$ \\
\hline & Yes & $260(100)$ & 21 (8.07) & $192(73.84)$ & $47(18.08)$ \\
\hline & Total & $260(100)$ & $21(8.07)$ & $192(73.84)$ & $47(18.08)$ \\
\hline \multirow[t]{3}{*}{ Efavirenz } & No & $80(30.77)$ & $0(0)$ & 69 (26.53) & $11(4.23)$ \\
\hline & Yes & $180(69.23)$ & $21(8.07)$ & $123(47.30)$ & $36(13.8)$ \\
\hline & Total & $260(100)$ & $21(8.07)$ & $192(73.84)$ & $47(18.08)$ \\
\hline \multirow[t]{3}{*}{ Emtricitabine } & No & $221(85)$ & 21 (8.07) & $167(64.23)$ & 33 (12.69) \\
\hline & Yes & 39 (15) & $0(0)$ & $25(9.6)$ & $14(5.38)$ \\
\hline & Total & $260(100)$ & 21 (8.07) & $192(73.84)$ & $47(18.08)$ \\
\hline \multirow[t]{3}{*}{ Nevirapine } & No & $200(76.92)$ & $21(8.07)$ & $143(55)$ & $36(13.84)$ \\
\hline & Yes & $60(23.08)$ & $0(0)$ & $49(18.84)$ & $11(4.23)$ \\
\hline & Total & $260(100)$ & 21 (8.07) & $192(73.84)$ & $47(18.08)$ \\
\hline
\end{tabular}

Key: $\mathrm{N}=$ Number.

Table 3: The frequency of occurrence of Streptococcus pneumoniae infection among the study Participants.

\begin{tabular}{|c|c|c|c|c|}
\hline Category & Number Examined (\%) & Number Positive (\%) & Number Negative (\%) & P-value \\
\hline \multicolumn{5}{|l|}{ Gender } \\
\hline Male & $88(33.8)$ & $4(1.54)$ & $84(32.26)$ & $0.050^{*} a$ \\
\hline Female & $172(66.2)$ & $17(6.54) \mathrm{a}$ & $155(59.66)$ & \\
\hline Total & $260(100.0)$ & $23(8.8)$ & $237(91.2)$ & \\
\hline \multicolumn{5}{|l|}{ Age Range } \\
\hline $18-37$ years & $104(40.0)$ & $12(4.6)$ & $92(35.4)$ & 0.399 \\
\hline $38-57$ years & $94(36.2)$ & $5(1.92)$ & $89(34.28)$ & \\
\hline $58-77$ years & $36(13.8)$ & $2(0.77)$ & $34(13.03)$ & \\
\hline $78-97$ years & $26(10.0)$ & $4(1.54)$ & $22(8.6)$ & \\
\hline Total & $260(100.0)$ & $23(8.8)$ & 237 (91.2) & \\
\hline \multicolumn{5}{|c|}{ Marital status } \\
\hline Single & $139(53.5)$ & $10(3.84)$ & $129(49.6)$ & 0.595 \\
\hline Married & $20(7.7)$ & $1(0.38)$ & $19(7.32)$ & \\
\hline
\end{tabular}




\begin{tabular}{|c|c|c|c|c|}
\hline Divorced & $40(15.4)$ & $5(1.92)$ & $35(13.46)$ & \\
\hline Separated & $57(21.9)$ & $6(2.3)$ & $51(19.6)$ & \\
\hline Widow & $4(1.5)$ & $1(0.38)$ & $3(1.12)$ & \\
\hline Total & $260(100.0)$ & $23(8.8)$ & $237(91.2)$ & \\
\hline \multicolumn{5}{|l|}{ Religion } \\
\hline Christianity & $139(53.5)$ & $13(5.0)$ & $126(48.5)$ & 0.385 \\
\hline Islam & $105(40.4)$ & $9(3.46)$ & $96(36.94)$ & \\
\hline Traditional & $16(6.2)$ & $1(0.38)$ & $15(5.82)$ & \\
\hline Total & $260(100.0)$ & $23(8.8)$ & 237 (91.2) & \\
\hline \multicolumn{5}{|l|}{ Tribe } \\
\hline Yoruba & $154(59.2)$ & $11(4.23)$ & $143(54.97)$ & 0.200 \\
\hline Igbo & $21(8.1)$ & $5(1.92)$ & $16(6.18)$ & \\
\hline Hausa & $33(12.7)$ & $1(0.38)$ & $32(12.32)$ & \\
\hline Others & $52(20.0)$ & $6(2.3)$ & $46(17.7)$ & \\
\hline Total & $260(100.0)$ & $23(8.8)$ & $237(91.2)$ & \\
\hline \multicolumn{5}{|c|}{ Educational Levels } \\
\hline None & $121(46.5)$ & $6(2.3)$ & $115(44.2)$ & 0.458 \\
\hline Primary & $26(10.0)$ & $2(0.77)$ & $24(9.23)$ & \\
\hline Secondary & $46(17.7)$ & $4(1.54)$ & $42(16.16)$ & \\
\hline Tertiary & $66(25.4)$ & $11(4.19)$ & $55(21.5)$ & \\
\hline Total & $260(100.0)$ & $23(8.8)$ & 237 (91.2) & \\
\hline \multicolumn{5}{|l|}{ Occupation } \\
\hline Self employed & $142(54.6)$ & $9(3.46)$ & $133(51.14)$ & $0.002^{*} b$ \\
\hline Trader & $20(7.7)$ & $1(0.38)$ & $19(7.32)$ & \\
\hline Student & $34(13.1)$ & $3(1.15)$ & 31 (11.95) & \\
\hline Civil Servant & $59(22.7)$ & $6(2.3)$ & $53(20.4)$ & \\
\hline Unemployed & $5(1.9)$ & $4(1.54)$ & $1(0.38)$ & \\
\hline Total & $260(100.0)$ & $23(8.8)$ & 237 (91.2) & \\
\hline
\end{tabular}

${ }^{*} P$-value $<0.05$ is considered statistically significant.

Lamivudine, Favirenz, Nevirapine and Efavirenz, 21 (8.07\%) of the participants were on double combinations of HAART, 192 (73.84\%) were on triple combinations, while 47 (18.08\%) were on quadriple combinations.

The frequency of occurrence of Streptococcus pneumoniae infection among the study participants is presented in Table 3. The number of female participants $(6.54 \%)$ who were positive were more than their male counterparts (1.54\%). On the basis of age distribution, participants in the 18-37 years age range had the highest occurrence of Streptococcus pneumoniae infection (4.6\%), while those within 58-77 years age range had the lowest occurrence $(0.77 \%)$. Based on marital status, the occurrence of Streptococcus pneumoniae infection was highest among the singles 10 (3.84\%), but lowest among the married and widows $(0.38 \%)$. With respect to religion, Streptococcus pneumoniae infection was higher among Christians with a prevalent rate of $5.0 \%$ and lowest among traditional worshippers with a prevalent rate of $0.38 \%$. On the basis of tribal identity, Yoruba participants were most affected (4.23\%), while Hausa participants were least affected (0.38\%). Occurrence of Streptococcus pneumoniae infection was highest among the self-employed (3.46\%) and lowest among the traders (0.38\%). The occurrence of Streptococcus pneumoniae infection was significantly associated $(P<0.05)$ with the gender and occupation of the participants, except age, marital status, religion, tribe and education level $(P>0.05)$.

Furthermore, the frequency of occurrence of $\mathrm{Myco}$ bacterium tuberculosis infection among the study participants is presented in Table 4. With regard to gender, the number of male participants (11.2\%) positive were significantly $(P>0.05)$ higher than their female counterparts $27(10.3 \%)$. On the basis of age distribution, participants belonging to the 38-57 years age range had the highest occurrence of Mycobacterium tuberculosis infection (9.6\%), while those within the $78-97$ years had the lowest frequency (0.38\%). Based on marital status, the occurrence of Mycobacterium tuberculosis infection was highest among the singles (10.4\%), but lowest among the widowed (0.77\%). Furthermore, with respect to religion, Mycobacterium tuberculosis infection was significantly higher $(\mathrm{P}<0.05)$ among Muslims with a prevalent rate of $11.5 \%$ compared to traditional worshippers with the lowest prevalent rate of $3.46 \%$. 
Table 4: Frequency of occurrence of Mycobacterium tuberculosis among the study participants.

\begin{tabular}{|c|c|c|c|c|}
\hline Characteristics & Number Examined (\%) & Number Positive (\%) & Number Negative (\%) & P-value \\
\hline \multicolumn{5}{|l|}{ Gender } \\
\hline Male & $88(33.8)$ & $29(11.2) \mathrm{a}$ & $59(22.7)$ & $0.001^{*} a$ \\
\hline Female & $172(66.2)$ & $27(10.3)$ & $145(55.8)$ & \\
\hline Total & $260(100.0)$ & $56(21.5)$ & $204(78.5)$ & \\
\hline \multicolumn{5}{|l|}{ Age Range } \\
\hline $18-37$ years & $104(40.0)$ & $24(9.2)$ & $80(30.8)$ & $0.046^{*} a$ \\
\hline $38-57$ years & $94(36.2)$ & $25(9.6) \mathrm{a}$ & $69(26.6)$ & \\
\hline $58-77$ years & $36(13.8)$ & $6(2.3)$ & $30(11.5)$ & \\
\hline $78-97$ years & $26(10.0)$ & $1(0.38)$ & $25(9.6)$ & \\
\hline Total & $260(100.0)$ & $56(21.5)$ & $204(78.5)$ & \\
\hline \multicolumn{5}{|l|}{ Marital status } \\
\hline Single & $139(53.5)$ & $27(10.4) a$ & $112(43.0)$ & $0.015^{\star} a$ \\
\hline Married & $20(7.7)$ & $6(2.3)$ & $14(5.4)$ & \\
\hline Divorced & $40(15.4)$ & $10(3.8)$ & $30(11.6)$ & \\
\hline Separated & $57(21.9)$ & $11(4.2)$ & $46(17.7)$ & \\
\hline Widow & $4(1.5)$ & $2(0.77)$ & $2(0.77)$ & \\
\hline Total & $260(100.0)$ & $56(21.5)$ & $204(78.5)$ & \\
\hline \multicolumn{5}{|l|}{ Religion } \\
\hline Christianity & $139(53.5)$ & $18(6.9)$ & $121(46.53)$ & $0.001^{*} a$ \\
\hline Islam & $105(40.4)$ & $29(11.5) \mathrm{a}$ & $76(29.23)$ & \\
\hline Traditional & $16(6.2)$ & $9(3.46)$ & $7(2.69)$ & \\
\hline Total & $260(100.0)$ & $56(21.5)$ & 204 (78.5) & \\
\hline \multicolumn{5}{|l|}{ Tribe } \\
\hline Yoruba & $154(59.2)$ & $44(16.9) \mathrm{a}$ & $110(42.3)$ & $0.009^{*} a$ \\
\hline Igbo & $21(8.1)$ & $5(1.92)$ & $16(6.18)$ & \\
\hline Hausa & $33(12.7)$ & $2(0.77)$ & 31 (11.93) & \\
\hline Others & $52(20.0)$ & $5(1.92)$ & $47(18.08)$ & \\
\hline Total & $260(100.0)$ & $56(21.5)$ & $204(78.5)$ & \\
\hline \multicolumn{5}{|c|}{ Educational Levels } \\
\hline None & $121(46.5)$ & $20(7.7) \mathrm{a}$ & $101(38.8)$ & $0.008^{*} a$ \\
\hline Primary & $26(10.0)$ & 7 (2.69) & $19(7.31)$ & \\
\hline Secondary & $46(17.7)$ & $18(6.9)$ & $28(10.8)$ & \\
\hline Tertiary & $66(25.4)$ & $11(4.23)$ & $55(21.18)$ & \\
\hline Total & $260(100.0)$ & $56(21.5)$ & $204(78.5)$ & \\
\hline \multicolumn{5}{|l|}{ Occupation } \\
\hline Self employed & $142(54.6)$ & $33(12.7)$ & 109 (41.9) & 0.329 \\
\hline Trader & $20(7.7)$ & $1(0.38)$ & $19(7.32)$ & \\
\hline Student & $34(13.1)$ & $8(3.07)$ & $26(10.03)$ & \\
\hline Civil Servant & $59(22.7)$ & $11(4.2)$ & $48(18.5)$ & \\
\hline Unemployed & $5(1.9)$ & $3(1.15)$ & $2(0.76)$ & \\
\hline Total & $260(100.0)$ & $56(21.5)$ & 204 (78.5) & \\
\hline
\end{tabular}

${ }^{*} P$-value $<0.05$ is considered statistically significant.

On the basis of tribal identity, Yoruba participants were most infected with Mycobacterium tuberculosis with a significant $(P<0.05)$ prevalent rate of $16.9 \%$. Majority of the positive participants had no formal education (7.7\%). The occurrence of Mycobacterium tuberculosis infection was significantly associated $(P<0.05)$ with the gender, age, religion, tribe and education level of the study participants, except occupation $(P>0.05)$.

In addition, the frequency of occurrence of Streptococcus pneumoniae and Mycobacterium tuberculosis co-infection among the study participants is presented in Table 5. Based on gender distribution, infection 
Table 5: Frequency of occurrence of Streptococcus pneumoniae and Mycobacterium tuberculosis co-infection among the study participants.

\begin{tabular}{|c|c|c|c|c|}
\hline Characteristics & Number Examined (\%) & Number Positive (\%) & Number Negative (\%) & $P$-value \\
\hline \multicolumn{5}{|l|}{ Gender } \\
\hline Male & $88(33.8)$ & $1(0.38)$ & $87(33.46)$ & $0.001^{*} a$ \\
\hline Female & $172(66.2)$ & $6(2.3) a$ & $166(63.8)$ & \\
\hline Total & $260(100.0)$ & $7(2.7)$ & $253(97.3)$ & \\
\hline \multicolumn{5}{|l|}{ Age Range } \\
\hline $18-37$ years & $104(40.0)$ & $1(0.38)$ & $103(39.6)$ & 0.077 \\
\hline $38-57$ years & $94(36.2)$ & $4(1.54)$ & $90(34.7)$ & \\
\hline 58-77 years & $36(13.8)$ & $2(0.77)$ & $34(13.03)$ & \\
\hline $78-97$ years & $26(10.0)$ & $0(0)$ & $26(10.0)$ & \\
\hline Total & $260(100.0)$ & $7(2.7)$ & $253(97.3)$ & \\
\hline \multicolumn{5}{|l|}{ Marital status } \\
\hline Single & $139(53.5)$ & $5(1.92) b$ & $134(51.58)$ & $0.038^{*} b$ \\
\hline Married & $20(7.7)$ & $0(0)$ & $20(7.7)$ & \\
\hline Divorced & $40(15.4)$ & $0(0)$ & $40(15.4)$ & \\
\hline Separated & 57 (21.9) & $2(0.77)$ & $55(21.13)$ & \\
\hline Widow & $4(1.5)$ & $0(0)$ & $4(1.5)$ & \\
\hline Total & $260(100.0)$ & $7(2.7)$ & $253(97.3)$ & \\
\hline \multicolumn{5}{|l|}{ Religion } \\
\hline Christianity & 139 (53. 5) & $2(0.77)$ & $137(52.73)$ & $0.001^{*} \mathrm{C}$ \\
\hline Islam & $105(40.4)$ & $5(1.92) c$ & $100(38.48)$ & \\
\hline Traditional & $16(6.2)$ & $0(0)$ & $16(6.2)$ & \\
\hline Total & $260(100.0)$ & $7(2.7)$ & $253(97.3)$ & \\
\hline \multicolumn{5}{|l|}{ Tribe } \\
\hline Yoruba & $154(59.2)$ & $7(2.7)$ & $147(56.5)$ & 0.060 \\
\hline Igbo & $21(8.1)$ & 0 & $21(8.1)$ & \\
\hline Hausa & $33(12.7)$ & 0 & $33(12.7)$ & \\
\hline Others & $52(20.0)$ & 0 & $52(20.0)$ & \\
\hline Total & $260(100.0)$ & $7(2.7)$ & $253(97.3)$ & \\
\hline \multicolumn{5}{|c|}{ Educational Levels } \\
\hline None & $121(46.5)$ & $4(1.54) d$ & $117(44.96)$ & $0.014^{*} \mathrm{~d}$ \\
\hline Primary & $26(10.0)$ & $0(0)$ & $26(10.0)$ & \\
\hline Secondary & $46(17.7)$ & $3(1.2)$ & $43(16.6)$ & \\
\hline Tertiary & $66(25.4)$ & $0(0)$ & $66(25.4)$ & \\
\hline Total & $260(100.0)$ & $7(2.7)$ & $253(97.3)$ & \\
\hline \multicolumn{5}{|l|}{ Occupation } \\
\hline Self employed & $142(54.6)$ & $5(1.9) \mathrm{e}$ & $137(52.7)$ & $0.024^{*} \mathrm{e}$ \\
\hline Trader & $20(7.7)$ & $0(0)$ & $20(7.7)$ & \\
\hline Student & 34 (13.1) & $0(0)$ & $34(13.1)$ & \\
\hline Civil Servant & $59(22.7)$ & $2(0.8)$ & 57 (21.9) & \\
\hline Unemployed & $5(1.9)$ & $0(0)$ & $5(1.9)$ & \\
\hline Total & $260(100.0)$ & $7(2.7)$ & 253 (97.3) & \\
\hline
\end{tabular}

${ }^{*} P$-value $<0.05$ is considered statistically significant.

was higher in female participants $(2.3 \%)$ than in their male counterparts $(0.38 \%)$. On the basis of age, infection was more common among participants belonging to the age range $38-57$ years (1.54\%), followed by 58 77 years $(0.77 \%)$. Howbeit, there was no occurrence of co-infection among the 78-97 years age range participants. Co-infection was highest among singles (1.92\%) and lowest among participants with "separated" marital status $(0.77 \%)$. There was no infection recorded among the married and divorced. Based on religion, 
Table 6: Relationship between occurrence of Streptococcus pneumoniae infection and indications for respiratory tract infection.

\begin{tabular}{|l|l|l|l|l|}
\hline Signs and symptoms & Number Examined N (\%) & No. Positive N (\%) & No. Negative N (\%) & $p$-value \\
\hline Chest Pain & $260(100.0)$ & $140(53.8)$ & $120(46.2)$ & $0.032^{*}$ \\
\hline Dyspnea & $260(100.0)$ & $20(7.7)$ & $240(92.3)$ & 0.528 \\
\hline Chills & $260(100.0)$ & $36(13.8)$ & $224(86.2)$ & 0.637 \\
\hline Bradypnea & $260(100.0)$ & $43(16.5)$ & $217(83.5)$ & 0.388 \\
\hline Fever & $260(100.0)$ & $5(1.9)$ & $255(98.1)$ & 0.415 \\
\hline Cough & $260(100.0)$ & $141(54.2)$ & $119(45.8)$ & $0.028^{*}$ \\
\hline Weight Loss & $260(100.0)$ & $21(8.1)$ & $239(91.9)$ & 0.704 \\
\hline Night Sweat & $260(100.0)$ & $39(15.0)$ & $221(85.0)$ & 0.358 \\
\hline None & $260(100.0)$ & $53(20.4)$ & $207(79.6)$ & 0.188 \\
\hline
\end{tabular}

${ }^{*} P$-value $<0.05$ is considered statistically significant.

Table 7: Relationship between occurrence of Mycobacterium tuberculosis and indications for Respiratory Tract Infection.

\begin{tabular}{|c|c|c|c|c|}
\hline Signs and symptoms & Total Number Examined N (\%) & Number Positive N (\%) & Number Negative $\mathbf{N}(\%)$ & $p$-value \\
\hline Chest Pain & $260(100.0)$ & $140(53.8)$ & $120(46.2)$ & $0.030^{*}$ \\
\hline Dyspnea & $260(100.0)$ & $20(7.7)$ & $240(92.3)$ & 0.061 \\
\hline Chills & $260(100.0)$ & $36(13.8)$ & $224(86.2)$ & 0.327 \\
\hline Bradypnea & $260(100.0)$ & $43(16.5)$ & $217(83.5)$ & 0.226 \\
\hline Fever & $260(100.0)$ & $5(1.9)$ & $255(98.1)$ & 0.294 \\
\hline Chronic Productive Cough & $260(100.0)$ & $141(54.2)$ & $119(45.8)$ & $0.026^{*}$ \\
\hline Weight Loss & $260(100.0)$ & $21(8.1)$ & $239(91.9)$ & 0.051 \\
\hline Night Sweat & $260(100.0)$ & $39(15.0)$ & $221(85.0)$ & 0.128 \\
\hline None & $260(100.0)$ & $53(20.4)$ & $207(79.6)$ & 0.709 \\
\hline
\end{tabular}

${ }^{*} P$-value $<0.05$ is considered statistically significant.

infection was highest among Muslims (1.92\%) and lowest among Christian participants $(0.77 \%)$. None $(0 \%)$ of the traditional worshippers were co-infected. On the basis of tribal identity, co-infection was only recorded among the Yoruba participants $(2.7 \%)$ and none among the non-Yoruba. The occurrence of Streptococcus pneumoniae and Mycobacterium tuberculosis co-infection among the study participants was significantly $(P<0.05)$ associated with gender, marital status, religion, educational level and occupation, except age and tribe $(P>$ 0.05).

Table 6 shows the relationship between occurrence of Streptococcus pneumoniae infection and indications for respiratory tract infection. Out of the 260 participants examined, 141 (54.2\%), 140 (53.8\%), 43 (16.5\%), 39 (15.0\%), 36 (13.8\%), 21 (8.1\%), 20 (7.7\%) and $5(1.9 \%)$ of them who tested positive to $S$. pneumoniae indicated cough, chest pain, bradypnea, night sweat, chills, weight loss, dyspnea and fever, respectively. 53 (20.4\%) had no signs and symptoms consistent with respiratory tract infection, although they were positive for S. pneumoniae.

Similarly, the relationship between occurrence of Mycobacterium tuberculosis infection and indications for respiratory tract infection is presented in Table 7. The most common indication among the participants who tested positive for $M$. tuberculosis was chronic productive cough $(54.2 \%)$, while the least was fever (1.9\%).

Table 8 represents the risk factors associated with the occurrence of Streptococcus pneumoniae and Mycobacterium tuberculosis infection among the study participants. $13.8 \%$ and $11.9 \%$ of the participants who tested positive for S. pneumoniae and M. tuberculosis, respectively have no knowledge of the organisms as etiologic agents of lower respiratory tract infection.

Out of the 260 participants examined, 34 (13.1\%) and 37 (14.2\%) indicated history of pneumonia and tuberculosis, while 70 (26.9\%) and 70 (26.9\%) indicated history of respiratory pathology and thoracic surgery, respectively. $36(13.8 \%)$ and 33 (12.7\%) of the participants who tested positive for $S$. pneumoniae and $M$. tuberculosis, indicated that they had not received BCG and pneumococcal vaccine, respectively.

70 (26.9\%) of the participants who tested positive for S. pneumoniae and M. tuberculosis, indicated that they never shared inhaler or respirator or consumed cigarette and alcohol. 134 (51.5\%) indicated that they went for medical check-ups less often.

Finally, the antibiotic sensitivity pattern of the Streptococcus pneumoniae isolates recovered from the sputum of HIV patients on HAART is represented with a histogram (Figure 1). 69.5\%, 69.5\%, 78.3\%, 65.2\%, 
Table 8: Risk factors associated with the occurrence of Streptococcus pneumoniae and Mycobacterium tuberculosis infection.

\begin{tabular}{|c|c|c|c|c|}
\hline Risk factors & Responses & $\begin{array}{l}\text { Number of } \\
\text { Participants }\end{array}$ & $\begin{array}{l}\text { No. Positive for } S \text {. } \\
\text { pneumoniae and } M \text {. } \\
\text { tuberculosis N (\%) }\end{array}$ & $\begin{array}{l}\text { No. Negative for } S \text {. } \\
\text { pneumoniae and } M \text {. } \\
\text { tuberculosis N (\%) }\end{array}$ \\
\hline \multirow{2}{*}{$\begin{array}{l}\text { Knowledge of Streptococcus } \\
\text { pneumoniae }\end{array}$} & Yes & $146(56.1)$ & $35(13.5)$ & $111(42.7)$ \\
\hline & No & $114(43.8)$ & $36(13.8)$ & $78(30.0)$ \\
\hline \multirow{2}{*}{$\begin{array}{l}\text { Knowledge of Mycobacterium } \\
\text { tuberculosis }\end{array}$} & Yes & $136(52.3)$ & $38(14.6)$ & $98(37.7)$ \\
\hline & No & $124(47.7)$ & $31(11.9)$ & $93(35.8)$ \\
\hline \multirow[t]{2}{*}{ History of pneumonia } & Yes & $146(56.1)$ & $34(13.1)$ & $112(43.1)$ \\
\hline & No & $114(43.8)$ & $36(13.8)$ & $78(30.0)$ \\
\hline \multirow[t]{2}{*}{ History of tuberculosis } & Yes & $136(52.3)$ & $37(14.2)$ & $97(37.3)$ \\
\hline & No & $124(47.7)$ & $33(12.7)$ & $91(35.0)$ \\
\hline \multirow[t]{2}{*}{ History of respiratory pathology } & Yes & $0(0)$ & $70(26.9)$ & $190(73.1)$ \\
\hline & No & $260(100)$ & $70(26.9)$ & $190(73.1)$ \\
\hline \multirow[t]{2}{*}{ Sharing inhaler or respirator } & Yes & $0(0)$ & $70(26.9)$ & $190(73.1)$ \\
\hline & No & $260(100)$ & $70(26.9)$ & $190(73.1)$ \\
\hline \multirow[t]{2}{*}{ Received BCG vaccine } & Yes & $134(51.5)$ & $37(14.2)$ & $97(37.3)$ \\
\hline & No & $126(48.5)$ & $33(12.7)$ & $93(35.8)$ \\
\hline \multirow[t]{2}{*}{ Received Pneumococcal vaccine } & Yes & $146(56.1)$ & $34(13.1)$ & $112(43.1)$ \\
\hline & No & $114(43.8)$ & $36(13.8)$ & $78(30.0)$ \\
\hline \multirow[t]{2}{*}{ History of thoracic surgery } & Yes & $0(0)$ & $70(26.9)$ & $190(73.1)$ \\
\hline & No & $260(100)$ & $70(26.9)$ & $190(73.1)$ \\
\hline \multirow[t]{2}{*}{ Smoke Cigarette } & Yes & $0(0)$ & $70(26.9)$ & $190(73.1)$ \\
\hline & No & $260(100)$ & $70(26.9)$ & $190(73.1)$ \\
\hline \multirow[t]{2}{*}{ Consume Alcohol } & Yes & $0(0)$ & $70(26.9)$ & $190(73.1)$ \\
\hline & No & $260(100)$ & $70(26.9)$ & $190(73.1)$ \\
\hline \multirow{3}{*}{$\begin{array}{l}\text { Frequency of medical check-up/ } \\
\text { laboratory tests }\end{array}$} & Less often & $134(51.5)$ & $36(13.8)$ & $98(37.7)$ \\
\hline & Often & $86(33.1)$ & $18(6.9)$ & $68(26.2)$ \\
\hline & Very often & $40(15.4)$ & $17(6.5)$ & $23(8.9)$ \\
\hline
\end{tabular}

$56.5 \%, 73.9 \%$ of the recovered S. pneumoniae isolates were sensitive to Ciprofloxacin, Erythromycin, Septrin, Ampiclox, Amoxycillin, and Gentamycin, respectively, while $30.5 \%, 30.5 \%, 21.7 \%, 34.8 \%, 43.5 \%$ and $26.1 \%$ of the isolates were resistant to Ciprofloxacin, Erythromycin, Septrin, Ampiclox, Amoxycillin, and Gentamycin, respectively.

\section{Discussion}

Mixed pulmonary infections with two or more pathogens are common in human immunodeficiency virus (HIV) patients, often presenting diagnostic difficulties for the clinician and resulting in potentially serious consequences for the patient if unrecognized $[8,38,39]$. When HIV infection is left untreated within the first ten years of infection, majority of the patients develop fatal opportunistic infections as a result of HIV induced deficiencies in the immune system. Streptococcus pneumoniae and Mycobacterium tuberculosis are two of the commonest causes of coinfection in HIV-seropositive patients in Sub-Saharan Africa, has contributing significantly to the mortality and morbidity rates of HIV/AIDS globally and may have similar clinical features and radiological appearances $[5,8,40,41]$.

This study examined the prevalence of Streptococcus pneumoniae and Mycobacterium tuberculosis coinfection among HIV infected Adult Patients on Highly Active Antiretroviral Therapy (HAART) in Ogun State, Nigeria. A prevalence rate of $8.8 \%, 21.5 \%$ and $2.7 \%$, were recorded for Streptococcus pneumoniae mono-infection, Mycobacterium tuberculosis monoinfection, as well as Streptococcus pneumoniae and Mycobacterium tuberculosis co-infection, respectively among the 260 participants recruited for the study. The frequency of occurrence of Streptococcus pneumoniae infection in this study was found to be lower than those of previous studies. For instance, Blossom, et al. [42], reported a prevalence rate of $18 \%$ among HIV positive Ugandan Patients. And in the same year, Cardoso and Colleagues [43] reported a prevalence rate of $28.6 \%$ among 0-18 years HIV positive Brazilian children. A much higher prevalence rate of $43.2 \%$ was observed by Conklin, et al. [44] in another study carried out ten years later among HIV-infected Kenya patients; in which Streptococcus pneumoniae was isolated from 237 out of 


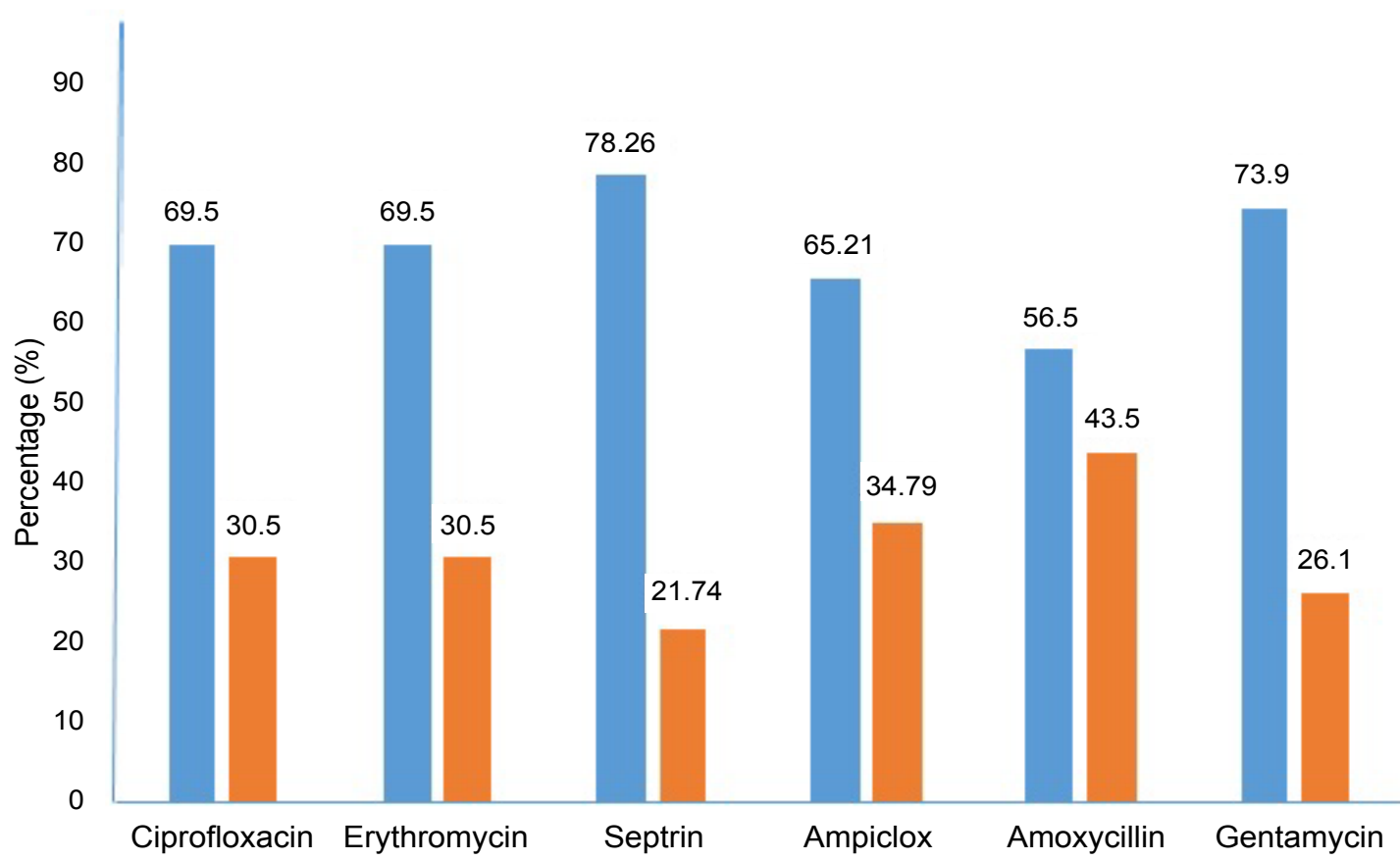

Figure 1: The antibiotic sensitivity pattern of Streptococcus pneumoniae isolates recovered from the sputum of HIV patients on HAART.

the 549 participants examined.

Regarding the occurrence of Mycobacterium tuberculosis among HIV patients on HAART, a prevalence rate of $21.5 \%$ was recorded in this present study which was found to be either lower or higher than reported in previous studies carried out in different geo-political zones of Nigeria. Lower prevalence rates previously reported include: $5.6 \%$ in Sokoto, North-West [45], $7.3 \%$ in Bauchi, North-West [46], 10.0\% in Kano, NorthWest [47], $12.0 \%$ in Ile-Ife, South-West [48], 12.8\% in Nasarawa, North-Central [25] and 16.9\% in PortHarcourt, South-South [49]. On the other hand, higher prevalence rates previously reported include: $25.1 \%$ in Lagos, South-West [50], 28.1\% in Ibadan, South-West [51], 29.3\% in Sagamu, South-West, [52], 44.2\% in Nasarawa, North-Central [53] and 71\% in Benue, NorthCentral [54]. Outside Nigeria, a lower prevalence rate of $12.3 \%$ was reported by Manjareeka, et al. [55] in a work carried out in East-India, while a higher prevalence rate of $42 \%$ was reported by Walter, et al. [56] among Iranian children infected with HIV. Although, it wasn't considered if the Iranian HIV infected children examined were on HAART or not. Nevertheless, there is evidence to support a reduction in vulnerability to tuberculosis in HIV-infected patients who have been initiated on HAART.

The TB-HIV co-infection prevalence rate recorded in this present study may have been influenced by the use and frequency of Anti-retroviral therapy drug combination among the study participants as shown in our Table 2.

Generally, the association between HIV infection and tuberculosis stems from two distinct processes.
In some cases, populations with latent tuberculosis acquire HIV infection, which increases 100 -fold the risk of reactivation of tuberculosis. In other cases, people with HIV-induced immunosuppression acquire new tuberculosis infections and are at extraordinarily high risk for active tuberculosis. This cycle of infection and disease is amplified by the interaction between patients with active tuberculosis and those with HIV infection in clinics, hospitals, and the broader community [11].

Furthermore, based on gender and age consideration, the results obtained in this current studies somewhat differ from those of previous studies. Our work suggest that TB-HIV co-infection is more prevalent among male subjects rather than females and among much older subjects. While we observed a prevalence rate of $10.3 \%$ and $11.2 \%$ for our female and male subjects, respectively, Oko-Jaja and Igbigbi [49] reported $9.0 \%$ and $7.9 \%$, respectively, Pennap, et al. [53] reported $44.8 \%$ and $38.30 \%$, respectively and Daniel, et al. [57] reported $57.3 \%$ and $42.7 \%$ for female and male subjects, respectively.

In addition, while we observed the highest occurrence of TB-HIV co-infection among patients aged 38-57 years (9.6\%), Pennap, et al. [53], recorded their highest occurrence among patients aged 21-40 years (45.30\%). Still, Oko-Jaja and Igbigbi [49] observed highest occurrence $(40.8 \%)$ among patients aged $31-45$ years. Our observation is not unconnected with progressive depreciation of the immune system associated with aging in the presence of the HIV.

Furthermore, the prevalence of Streptococcus pneumoniae and Mycobacterium tuberculosis coinfection in HIV patients on HAART as observed in 
this present study was $2.7 \%$. It appears that this present work is the first to examine the prevalence of Streptococcus pneumoniae and Mycobacterium tuberculosis co-infectivity among HIV patients on HAART. Nevertheless, it is important to mention the outcome of similar work done by previous researchers.

For instance, Ihongbe, et al. [5], in their work titled, "Pneumococcal pneumonia complicates presentation of pulmonary tuberculosis and pseudomembranous candidiasis, predictive of unknown HIV infection in Ekpoma, Nigeria", reported that $44.1 \%$ of their subjects were co-infected with Streptococcus pneumoniae and Mycobacterium tuberculosis, while $40.2 \%$ had M. tuberculosis and C. albicans. Moreover, out of 260 patients clinically diagnosed with pulmonary tuberculosis, $23.1 \%$ had Streptococcus pneumoniae, while $69.3 \%$ of 150 patients clinically diagnosed with pneumonia had $M$. tuberculosis. Their study also shows that exactly $79.2 \%$ of the 240 patients with Pseudomembranous candidiasis (PC), had undetected HIV. They therefore concluded that pneumococcal pneumonia complicated clinical diagnosis of pulmonary tuberculosis, while PC was $79.2 \%$ predictive of undiagnosed HIV infection.

In a particular case presentation of a patient with features of advanced HIV infection, Louw and Tikly [8], attributed the aetiology of purulent pericarditis to co-infection with Streptococcus pneumoniae and Mycobacterium tuberculosis.

Regarding indications for respiratory tract infection caused by Streptococcus pneumoniae and Mycobacterium tuberculosis as observed in this study, they were somewhat different from those reported by Lin, et al. [39]. The frequency of signs and symptoms as indicated by our participants were: chest pain (53.8\%), fever (1.9\%), chronic productive cough (54.2\%) and weight Loss (8.1\%); whereas it was $11.1 \%, 42.6 \%, 90.7 \%$ and $13.0 \%$, respectively as reported by Lin, et al. [39].

The high prevalence of $S$. pneumoniae and $M$. tuberculosis among the participants in this current study can be attributed to the following possible risk factors: 1) Existence of poor knowledge and awareness of the pathogens among some of the participants, $13.8 \%$ and $11.9 \%$, respectively; 2 ) History of pneumonia and tuberculosis, $13.1 \%$ and $14.2 \%$, respectively; 3 ) No history of Pneumococcal and BCG vaccines, $12.7 \%$ and $13.8 \%$, respectively and 4 ) poor attitude towards medical check-up/laboratory tests (13.8\%). Howbeit, none of the participants indicated history of respiratory pathology/thoracic surgery, sharing of inhaler or respirator, smoking of cigarette or drinking of alcohol.

The antibiotic sensitivity pattern of the Streptococcus pneumoniae isolates recovered from the sputum of the HIV patients on HAART is represented with a histogram (Figure 1). 69.5\%, 69.5\%, 78.3\%, 65.2\%, 56.5\%, 73.9\% of the recovered S. pneumoniae isolates were sensitive to Ciprofloxacin, Erythromycin, Septrin, Ampiclox, Amoxycillin, and Gentamycin, respectively, while 30.5\%, $30.5 \%, 21.7 \%, 34.8 \%, 43.5 \%$ and $26.1 \%$ of the isolates were resistant to Ciprofloxacin, Erythromycin, Septrin, Ampiclox, Amoxycillin, and Gentamycin, respectively. This is partly comparable with the work of Ojo-Bola and Oluyege [58], who tested isolates of S. pneumoniae recovered from the sputum of HIV/AIDS patients in South-western Nigeria against the following antibiotics: Streptomycin, Gentamycin, Augmentin, Cefixime, Ceftazidime, Cefepime, Ceftriaxone, Cefuroxime, Ciprofloxacin, Sparfloxacin, Perfloxacin, Levofloxacin, Cotrimoxazole, Penicillin G, Amoxycillin, Clarithromycin, Erythromycin, Azithromycin, Chloramphenol and Tetracycline. The outcome of their work shows that's $12.5 \%, 6.3 \%, 12.5 \%, 31.3 \%, 25.0 \%, 6.3 \%$ and $6.3 \%$ were resistant to $9,8,7,6,5,4$ and 3 classes of antibiotics mentioned above, respectively. Similarly, in a study carried out in North Western Nigeria within 2009 and 2011 by Iliyasu, et al. [59], a total of 117 S. pneumoniae isolates were recovered from sputum samples, $16.7 \%$ were sensitive to penicillin while $55.3 \%$ were intermediate and $28.0 \%$ were resistant, only $3.8 \%$ were sensitive to cotrimoxazole while $78.8 \%$ were sensitive to amoxicillin, $12.9 \%$ were intermediate and $8.5 \%$ were resistant.

Generally, a pathogen reported as 'resistant' implies that the infection it has caused will not respond to treatment with the drug to which it is resistant irrespective of dose or site of infection. On the other hand, a pathogen reported as susceptible suggests that the infection it has caused is likely to respond to treatment when the drug to which it is susceptible was used in normal recommended doses and administered by an appropriate route $[18,37]$.

It has been posited that underlying pneumococcal pneumonia could pose a problem in treatment of tuberculosis patients and also progression from asymptomatic to symptomatic tuberculosis could complicate pneumonia cases if undetected. Etiologic agent of underlying infections may as well develop antibiotic resistance because while treating clearly diagnosed infection, an etiologic agent of underlying or asymptomatic infection may develop resistance after prolonged exposure to antibiotics. Thus, prolonged usage of these antibiotics may lead to development of multidrug resistance in an organism [5].

Finally, current treatment guidelines for HIV/ AIDS by WHO recommend the use of a combination of at least 3 ARV drugs which include: 2 Nucleoside Reverse Transcriptase Inhibitors (NRTIs) combined with 1 medication from either of the 2 remaining classes; the Non-Nucleoside Reverse Transcriptase Inhibitors (NNRTIs) or the Protease Inhibitors (PIs). When such drugs, typically three or four, are taken in 
combination, the approach is known as highly active antiretroviral therapy - HAART. A combination of Nevirapine, Stavudine, and Lamivudine or Lamivudine with Zidovudine is frequently prescribed [60,61].

According to a research study carried out separately by Saindou, et al. [62] and Dodd, et al. [63], it was observed that there was a significant reduction in the incidence rate of Streptococcus pneumoniae and Mycobacterium tuberculosis infection in HIV infected patients after the introduction of HAART. However, despite the declines in the incidence rate of Streptococcus pneumoniae and Mycobacterium tuberculosis infection with HAART, the two pathogens have continued to cause morbidity and mortality among HIV-infected subjects [40]. Further research is needed to clarify the effects of other factors in the prevention of Streptococcus pneumoniae and Mycobacterium tuberculosis infection among patients with HIV, such as BCG/Pneumococcal vaccination and antibiotic resistance in the HAART era.

\section{Conclusion}

The outcome of this work shows that Streptococcus pneumoniae and Mycobacterium tuberculosis coinfection exist among HIV adult patients on HAART with a prevalence rate of $2.7 \%$ which was found to be significantly $(P<0.05)$ associated with the gender, marital status, religion, educational level and occupation of the participants; except age and tribe. Identified risk factors include: poor knowledge and awareness of the pathogens, history of pneumonia and tuberculosis infection, lack of pneumococcal and BCG vaccination, less frequency of medical check-up/laboratory tests among several others. The Streptococcus pneumoniae isolates were most sensitive to Septrin (78.3\%) and least sensitive to Amoxycillin (56.5\%). Early diagnosis and proper treatment monitoring condition must still be viewed with great concern with serious public enlightenment campaign efforts to eradicate these twin devastating pulmonary diseases among HIV positive populace.

\section{Limitation of the Study}

Culture, isolation and antibiotic sensitivity testing of Mycobacterium tuberculosis was not done due to lack of facility and cost of testing. Detection of Mycobacterium tuberculosis infection among the HIV positive adult patients on HAART was carried out using only the ZiehlNeelson staining technique. Still only HIV-positive adults on HAART at one HIV Clinic in Ogun State were sampled, this may have undermined the prevalence rate reported in this study.

\section{Recommendation}

In the light of the above, we therefore recommend that future Researchers should employ more sensitive techniques such as the Polymerase Chain Reaction and Gene Expert in the detection, identification and characterization of Mycobacterium tuberculosis isolates alongside the cultural diagnosis where facility for such is available. A multicentre research involving more HIV Clinics in Ogun State is also been advocated for. Still, similar studies like this should be carried out in other geopolitical zones of the country as there were scarcity of data as at the time of this research.

\section{Acknowledgement}

The authors acknowledge the Management and Staff of Babcock University Teaching Hospital (BUTH), IlishanRemo, Ogun State, Nigeria for their cooperation and support towards the success of this study, particularly those in the Department of Community Medicine and Medical Microbiology.

\section{Authors' Contributions}

This work was carried out in collaboration between all authors. Authors ESS and AOA designed the study, performed the statistical analysis, wrote the protocol and wrote the first draft of the manuscript. Author IHC managed the analyses of the study. Author OA managed the literature searches. All authors read and approved the final manuscript.

\section{Conflict of Interest}

The authors declare they have no competing interests.

\section{References}

1. Digban AK, Osula I, Adesina EB, Aghatise K, Enitan SS (2017) Assessment of CD4 count and some haematological parameters of HIV positive patients co-infected with Hepatitis B virus in Osun state, Nigeria. International Blood Research \& Reviews 7: 1-13.

2. Olayanju AO, Afolabi T, Ezigbo ED, Enitan SS, Oluwatayo BO (2018) Assessment of antiphospholipid antibodies, CD4 count and some haematological parameters in HIV patients attending a tertiary health institution in south-western Nigeria. International Blood Research \& Review 8: 1-14.

3. Gingo MR, Morris A (2013) Pathogenesis of HIV and the Lung. Curr HIVIAIDS Rep 10: 42-50.

4. Crothers K, Bruce WT, Burkhardt K, Morris A, Flores SC, et al. (2011) HIV-associated lung infections and complications in the era of combination antiretroviral therapy. Proc Am Thorac Soc 8: 275-281.

5. Ihongbe JC, Agwu E, Inyang N (2007) Pneumococcal pneumonia complicates presentation of pulmonary tuberculosis and pseudomembranous candidiasis, predictive of unknown HIV Infection in Ekpoma Nigeria. The Internet Journal of Microbiology 5: 1-7.

6. Wallace JM, Rao VA, Glassroth J, Hansen NI, Rosen MJ, et al. (1993) Respiratory Illness in persons with human immunodeficiency virus infection. Am Rev Respir Dis 148: 1523-1529.

7. Sepkowitz KA (2001) AIDS-The First 20 Years. N Engl J Med 344: 1764-1772.

8. Louw A, Tikly M (2007) Purulent pericarditis due to co-infection with Streptococcus pneumoniae and Mycobacterium tuberculosis in a patient with features of advanced HIV 
infection. BMC Infect Dis 7: 1471-2334.

9. Jolobe OMP (2015) Dual infection with S. pneumoniae and $M$. tuberculosis was also a possibility. International Journal of Cardiology 201: 184.

10. Jolobe OMP (2018) Dual infection in tuberculous with pneumonia. International Journal of Medicine 111: 349.

11. Richard EC, Neil AM (2008) Tuberculosis in africacombating an HIV drive crisis. N Engl J Med 358: 10891092.

12. Iliyasu G, Mohammad FD, Habib AG (2017) Community acquired pneumococcal pneumonia in northwestern Nigeria: Epidemiology, antimicrobial resistance and outcome. Afr J Infect Dis 12: 15-19.

13. Nester EW, Roberts CE, Pearsall NN, Anderson DG, Nester MT (2004) Pneumococcal pneumonia. In: Keven TK, Ronald EW, Terrance S, Jodi KB, Microbiology: A Human Perspective. ( $3^{\text {rd }}$ edn), James MS, Von Hoffman Press, Inc, University of Washington, New York, 218-221.

14. Carroll KC, Jeffery AH, Miller S (2016) Streptococcus Pneumoniae. In: Carroll KC, Morse SA, Mietzner T, Miller S, Jawetz Melnick \& Adelbergs Medical Microbiology. (27 $7^{\text {th }}$ edn), McGraw-Hill Education, China, 218-222.

15. Janoff EN, Breiman RF, Daley CL, Hopewell PC (1992) Pneumococcal disease during HIV Infection: Epidemiologic, clinical, and immunologic prospectives. Ann Intern Med 117: 314-324.

16. Mao C, Harper M, Mcintosh K, Reddington C, Cohen J, et al. (1996) invasive pneumococcal infection in human immunodeficiency virus-infected children. J Infect Dis 173: 870-876.

17. Feldman C (2005) Pneumonia associated with HIV infection. Curr Opin Infect Dis 18: 165-170.

18. Frankel RE, Virata M, Hardalo C, Altice FL, Friedland G (1996) Invasive pneumococcal disease: Clinical features, serotypes, and antimicrobial resistance patterns in cases involving patients with and without human immunodeficiency virus infection. Clin Infect Dis 23: 577-584.

19. Hirschtick RE, Glassroth J, Jordan C (1995) Bacterial pneumonia in persons infected with the human immunodeficiency virus. N Engl J Med 333: 845-851.

20. Gebo KA, Moore RD, Keruly JC, Chaisson RE (1996) Risk factors for pneumococcal disease in human immunodeficiency virus-infected patients. J Infect Dis 173 857-862.

21. Madeddu G, Fiori LM, Mura SM (2010) Bacterial communityacquired pneumonia in HIV-infected patients. Curr Opin Infect Dis 16: 201-207.

22. Daley CL (1998) Pneumococcal Infection and HIV. HIV InSite Knowledge base chapter. Comprehensive, up-todate information on HIVIAIDS treatment and prevention from the University of California San Francisco, USA.

23. Serafino-wani RL (2013) Tuberculosis: Pathophysiology and microbiology of pulmonary tuberculosis. South Sudan Medical Journal 6: 10-12.

24. WHO (2011/2012) Tuberculosis Global Facts. World Health Organization, Geneva Switzerland.

25. Umeh EU, Ishaleku D, Iheukwumere CC (2007) HIVI Tuberculosis co-infection among patients attending a referral chest clinic in Nasarawa State, Nigeria. Journal of Applied Sciences 7: 933-935.

26. Crook AM, Turkova A, Musiime V, Mutsa Bwakura-
Dangarembizi, Sabrina Bakeera-Kitaka, et al. (2016) Tuberculosis incidence is high in HIV- infected African children but is reduced by co-trimoxazole and time on antiretroviral therapy. BMC Med 14: 50.

27. Cheesbrough M (2006a) Mycobacterium tuberculosis and HIV. In: Cheesbrough M, District Laboratory Practice in Tropical Countries, Part 2. ( $2^{\text {nd }}$ edn), Cambridge University Press, Edinburgh Building, Cambridge, UK, 207.

28. GHELC (2013) Tuberculosis Basics. Global Health eLearning Centre, USAID.

29. WHO Stop TB Partnership (2006) The Global Plan to Stop TB. 2006-2015, World Health Organization, Geneva Switzerland.

30. Joan-Pau M, Angels O, Patricia GD, Vicente M, Antonio $M$, et al. (2014) The current status of TB in the world: The influence of poverty, prisons, HIV, Immigration and control Programmes.

31. Shimazaki T, Taniguchi T, Saludar NRD, Gustilo ML, Kato T, et al. (2018) Bacterial co-infection and early mortality among pulmonary tuberculosis patients in manila, Philippines. Int J Tuberc Lung Dis 22: 65-72.

32. Adejumo OA, Daniel OJ, Otesanya FA, Adegbola AA Dacosta A, et al. (2017) Factors associated with TB/HIV Co-infection among drug sensitive tuberculosis patients managed in a secondary health facility in lagos, Nigeria. Afr $\mathrm{J}$ Infect Dis 11: 75-82.

33. Cheesbrough M (2006b) Microscopic Techniques in Microbiology. In: Cheesbrough M, District Laboratory Practice in Tropical Countries, Part 2. ( $2^{\text {nd }}$ edn), Cambridge University Press, Edinburgh Building, Cambridge, UK, 3560.

34. Joon YS, Byung WE, Moon HN (2013) Diagnosis of pneumococcal pneumonia: Current pitfalls and the way forward. Infect Chemother 45: 351-366.

35. Cheesbrough M (2006c) Biochemical test to identify bacteriac. In: Cheesbrough M, District Laboratory Practice in Tropical Countries, Part 2. ( $2^{\text {nd }}$ edn), Cambridge University Press, Edinburgh Building, Cambridge, UK, 62-75.

36. Bauer AW, Kirby WMM, Sherris JC, Turck M (1966) Antibiotic susceptibility testing by a standardized single disk method. Am J Clin Pathol 45: 493-496.

37. Cheesbrough M (2006d) Antimicrobial susceptibility testing. In: Cheesbrough M, District Laboratory Practice in Tropical Countries, Part 2. (2 ${ }^{\text {nd }}$ edn), Cambridge University Press, Edinburgh Building, Cambridge, UK, 132-142.

38. Schleicher GK, Feldman C (2003) Dual infection with streptococcus pneumoniae and mycobacterium tuberculosis in HIV-seropositive patients with community acquired pneumonia. Int J Tuberc Lung Dis 7: 1207-1208.

39. Lin G, Chang F, Chou C, Lin Y, Chih-Hung K (2011) Characteristics and Outcome of patients with dual pulmonary tuberculosis and non-mycobacterial respiratory infections. J Clin Med Res 3: 309-318.

40. Rabie H, Goussard $P$ (2016) Tuberculosis and pneumonia in HIV infected children: An overview. Pneumonia 8: 19

41. Sheikholeslami MF, Sadraei J, Farnia P, Moghadam MF, Kochak HE (2015) Co-infection of mycobacterium tuberculosis and pneumocystis jirovecii in iranian patients with human immunodeficiency virus. J Microbiol 8: 17254

42. Blossom DB, Namayanja-Kaye G, Nankya-Mutyoba J, Mukasa JB, Bakka H, et al. (2006) Oropharyngeal colonization by streptococcus pneumoniae among HIV- 
infected adults in Uganda: Assessing prevalence and antimicrobial susceptibility. Int J Infect Dis. 10: 458-464.

43. Cardoso VC, Cervi MC, Cintra OAL, Salathiel ASM, Gomes CLF (2006) Nasopharyngeal colonization with streptococcus pneumoniae in children infected with human immunodeficiency virus. J Pediatr 82: 51-57.

44. Conklin ML, Bigogo G, Jagero G, Hampton L, Junghae $M$, et al. (2016) High Streptococcus pneumoniae colonization prevalence among HIV-infected Kenyan parents in the year before pneumococcal conjugate vaccine introduction. BMC Infect Dis 16: 1312-1322.

45. Isaac IZ, John RT, Udomah FP, Erhabor O (2016) Tuberculosis ad HIVAIDS co-infection rate among Tuberculosis patients in Sokoto TB Centre, North Wester Nigeria. BJMLS 1: 40-46.

46. Iliayasu MY, Abbas HM, Ashiegu JN (2016) Prevalence of HIVIAIDS and pulmonary tuberculosis co-infection among patients attending some health centres of bauchi metropolis. Pyrex Journal of Microbiology and biotechnology Research 2: 15-21.

47. Iliyasu Z, Babashani M (2009) Prevalence and predictors of TB co-infection among HIV seropositive patients attending aminu kano teaching hospital, northern Nigeria. J Epidemiol 19: 81-87.

48. Onipede AO, Idigbe O, Ako-Nai AK, Omojola O, Oyelese AO, et al. (1999) Sero-prevalence of HIV antibodies in TB patients in Ile-Ife. East Afr Med J 76: 127-132.

49. Oko-Jaja RI, Igbigbi EE (2017) Pattern and prevalence of HIV and tuberculosis in port-harcourt Nigeria. International Journal of Novel Research in Healthcare and Nursing 4 $1-6$.

50. Mattew AO, Gbenga AO, Olamide SO, Alaka-Coker AA Idris MG, et al. (2015) Tuberculosis and HIV co-infection among patients attending directly observed treatment short course (DOTS) in Lagos, Nigeria. Archives of Applied Science Research 7: 69-74.

51. Odaibo GN, Gboun MF, Ekanem EE, Gwarzo SN, Saliu I, et al. (2006) HIV Infection among Patients with PTB in Nigeria. Afr J Med Med Sci 35: 93-98.

52. Kolade OR, Atilola OG, Babalola TV, Komolafe OI (2016) Prevalence of HIV infection among tuberculosis patients in a teaching hospital in south-west Nigeria: A four-year retrospective study. HIV \& AIDS Review 15: 136-140.
53. Pennap G, Makpa S, Ogbu S (2010) Sero-prevalence of HIV Infection among tuberculosis patients in a rural tuberculosis referral clinic in northern Nigeria. Pan Afr Med J 5: 22.

54. Iheanacho SN, Simidele MO, Ngbede MA, Thaddeus I (2017) Mycobacterium tuberculosis ad HIV-Co-infections among patients attending a Nigeria Tertiary Health Center. International Journal of Tropical Disease and Health 24: 1-8.

55. Manjareeka M, Nanda S (2013) Prevalence of HIV Infection among tuberculosis patients in eastern India. J Infect Public Health 6: 358-362.

56. Walters E, Cotton MF, Rabie H, Schaaf HS, Walters LO, et al. (2008) Clinical presentation and outcome of tuberculosis in human immunodeficiency virus infected children on antiretroviral therapy. BMC Pediatr 8: 1471-2431.

57. Daniel OJ, Oladapo OT, Salako AA, lyaniwura CA, Oluwole FA (2005) Gender and TB/HIV co-infection: Presentation and Treatment Outcome in Nigeria. Nigeria Medical Practitioner 47: 58-60.

58. Ojo-Bola O, Oluyege AO (2014) Antibiotics Resistance of Bacteria Associated with pneumonia in HIVIAIDS Patients in Nigeria. American Journal of Infectious Diseases and Microbiology 2: 138-144.

59. Iliayasu G, Habib AG, Mohammad AB (2015) Antimicrobial susceptibility pattern of invasive pneumococcal isolates in north west, Nigeria. J Glob Infect Dis 7: 70-74.

60. Itodo GE, Enitan SS, Samanu VO, Ehiaghe FA, Akele YR, et al. (2015) Effect of highly active antiretroviral therapy (HAART) On CD4+ cell count and liver enzymes in HIV infection at Lokoja, Nigeria. African Journal of Cellular Pathology 4: 34-41.

61. Akele RY, Olayanju AO, Bala ND, Chollom SC, Enitan SS, et al. (2015) Haematological parameters in Human Immunodeficiency Virus positive individuals on different HAART regimen. World Journal of Pharmaceutical Research 4: 3042.

62. Saindou M, Chidiac C, Miailhes $P$, Voirin N, Baratin D, et al. (2008) Pneumococcal pneumonia in HIV-infected patients by antiretroviral therapy periods. HIV Med 9: 203-207.

63. Dodd PJ, Prendergast AJ, Beecroft C, Kampmann B, Seddon JA (2017) The impact of HIV and antiretroviral therapy on TB risk in children: A systematic review and meta-analysis. Thorax. 